\title{
Association of VEGFA polymorphisms with susceptibility and clinical outcome of hepatocellular carcinoma in a Chinese Han population
}

\author{
Fei Liu ${ }^{1, *}$, Limei Luo ${ }^{2,}{ }^{*}$, Yonggang Wei ${ }^{1}$, Wentao Wang ${ }^{1}$, Tianfu Wen ${ }^{1}$, Jiayin Yang ${ }^{1}$, \\ Mingqing $X \mathbf{u}^{1}$, Bo Li $^{1}$ \\ ${ }^{1}$ Department of Liver Surgery and Liver Transplantation Center, West China Hospital, Sichuan University, Chengdu, 610041, \\ Sichuan Province, China \\ ${ }^{2}$ Department of Clinical Immunological Laboratory, West China Hospital, Sichuan University, 610041, China \\ *These authors contributed equally to this work \\ Correspondence to: Bo Li, email: cdlibo688@163.com \\ Yonggang Wei, email: wyonggang688@163.com
}

Keywords: hepatocellular carcinoma, VEGFA, polymorphism, susceptibility, clinical outcome

Received: September 06, $2016 \quad$ Accepted: January 16, 2017

Published: January 27, 2017

\section{ABSTRACT}

Vascular endothelial growth factor A (VEGFA) is an important angiogenesis regulator, which plays an important role in angiogenesis and progression of tumor, including hepatocellular carcinoma (HCC). We aimed at determining whether single nucleotide polymorphisms of VEGFA gene influence the development and clinical outcomes of HCC. We analyzed four potential functional polymorphisms $(936 \mathrm{C} / \mathrm{T}$, 634G/C, 1612G/A, 2578C/A) of VEGFA gene in 476 HCC patients and 526 controls using matrix-assisted laser desorption ionization time-of-flight mass spectrometry method. Serum VEGF levels were measured by enzyme-linked immunosorbent assay. The Kaplan-Meier methods with log-rank test and Cox regression models were used to compare survival of resected HCC patients according to the genotype. We found that only the VEGFA $2578 \mathrm{C} / \mathrm{A}$ polymorphism was significantly associated with decreased risk of HCC (AA/AC vs. CC; adjusted OR $=0.69,95 \% \mathrm{CI}=0.51-0.93$ ). Furthermore, the $2578 \mathrm{C} / \mathrm{A}$ polymorphism was associated with significantly decreased postoperative recurrence (AA/AC vs. CC, adjusted $O R=0.51 ; 95 \% C I, 0.29-0.88$ ) and improved overall survival (AA/AC vs. CC, adjusted $H R=0.27,95 \% \mathrm{CI}=0.13-0.52$ ) of resected HCC patients. In addition, the VEGF serum levels in HCC patients were significantly higher than those in healthy controls, although no significant association between VEGFA genotype and serum levels of VEGF was observed. These results suggest that the VEGFA $2578 \mathrm{C} / \mathrm{A}$ polymorphism may play a potential role in the development and clinical outcome of HCC among Chinese Han population.

\section{INTRODUCTION}

Liver cancer in men is the fifth most common cancer and the second-leading cause of cancer-related death worldwide [1]. Among primary liver cancers, hepatocellular carcinoma (HCC) is responsible for $70 \%$ $-90 \%$ of the total liver cancer burden worldwide [2]. The pathogenesis of HCC is not completely understood, but it is thought to be a multistage process with the complex interactions of various risk factors including infection with hepatitis B virus (HBV) and/or hepatitis C virus (HCV), cirrhosis, male gender, concurrent alcohol use, aflatoxin B1 intake and multiple genetic variants [3-5]. However, only a fraction of HBsAg carriers eventually develop $\mathrm{HCC}$ and only $2.5 \%$ of HCV infected individuals develop HCC later in life [6]. Moreover, the variability in outcome following the same environmental exposure and the clustering of HCC within families were observed [7-10], which suggested that host genetic factors may affect HCC development.

Angiogenesis, which defined as the formation of new blood vessels from existing vasculature, represents an essential process in the pathogenesis of cancer, since newly formed vessels promote tumor growth by supplying oxygen and nutrients. HCC is a typical hypervascular tumor, and a radiology finding of an arterial hypervascular 
pattern is a diagnostic criterion for HCC [11].Vascular endothelial growth factor (VEGF) is a major driver of physiological and pathological angiogenesis [12]. VEGF plays an important role in tumor angiogenesis through promoting endothelial cell growth and migration [13]. VEGF is expressed by several tumors at higher levels than when it appears in normal tissues, and its overexpression suggests unfavorable prognosis $[14,15]$. The expression levels of VEGFA mRNA in HCC was 6.95-fold higher than in HBsAg-negative healthy individuals [15]. The serum concentrations of VEGF-A have been found elevated in $\mathrm{HCC}$ in parallel with the tumoral grading, and they are considered independent markers of prognosis and survival [16].

The human VEGF gene is located on chromosome 6 p21.3 [17] which is highly polymorphic. To date, it has been reported that there are at least 20 potential functional single nucleotide polymorphisms (SNPs) in VEGF gene. Among them, -2578C $>\mathrm{A}$ (rs699947), -634G $>\mathrm{C}$ (rs2010963), -1612 G/A (rs10434), and -936C $>\mathrm{T}$ (rs3025039) were demonstrated to regulate VEGF expression $[18,19]$. Accordingly, these polymorphisms may affect VEGF protein concentrations influencing the angiogenesis process and may be related to inter individual variations in tumor risk, progression, and prognosis. In recent years, the VEGF SNPs have been reported to be associated with cancers of the lung [20], colorectum [21], breast, and bladder [22-23]. Moreover, the VEGF SNPs have also been reported to be associated with clinical outcome of esophageal cancer, renal cell carcinoma and non-small cell lung cancer [24-26].

Till date, the association between VEGF SNPs and HCC risk is still controversial and ambiguous [15, 27-28]. Meanwhile, the association between VEGF SNPs and HCC prognosis is also obscure [29-31]. Moreover, no study had investigated the association of VEGF SNPs with risk and clinical prognosis of HCC simultaneously in the same cohort patients. Therefore, we performed a study to comprehensively evaluate the association of VEGF $-936 \mathrm{C}>\mathrm{T},-634 \mathrm{G}>\mathrm{C},-1612 \mathrm{G} / \mathrm{A}$ and $-2578 \mathrm{C}>\mathrm{A}$ polymorphisms with susceptibility and clinical outcome of HCC in a Chinese Han population.

\section{RESULTS}

\section{Characteristics of studies population}

The baseline characteristics of the 476 HCC cases and 526 controls are summarized in Supplementary Table 3. No significant differences between the two groups in terms of age, gender,drinking status and family history of cancer distribution. However, as shown in Supplementary Table 3, there was significant difference between cases and controls in the distribution of smoking and HBV carrier state. The HCC patient characteristics and clinical features of the tumor are summarized in Supplementary Table 4 . Of the 476 patients, 222 had their primary tumor surgically resected; the remaining 254 patients underwent local therapy such as transarterial embolization, radiofrequency ablation, or conservative management. We followed HCC patients to December 2012 and the median follow-up period was 22 months (range: 3-62 months).

\section{Genotypes frequency and effects on the development of HCC}

The genotype distributions of VEGF $-936 \mathrm{C}>\mathrm{T}$, $-634 \mathrm{G}>\mathrm{C},-1612 \mathrm{G} / \mathrm{A}$ and $-2578 \mathrm{C}>\mathrm{A}$ polymorphisms in the cases and the controls were shown in Table 1. The distributions of these genotype frequencies in controls were all in $\operatorname{HWE}(P=0.54,0.94,0.88$ and 0.88 for $-936 \mathrm{C}>\mathrm{T},-634 \mathrm{G}>\mathrm{C},-1612 \mathrm{G} / \mathrm{A}$ and -2578 $\mathrm{C}>\mathrm{A}$, respectively). In the overall analysis, we found that only the $-2578 \mathrm{C}>\mathrm{A}$ was significantly associated with the development of HCC. Supplementary Figure 1 shows the three genotypes for VEGF $-2578 \mathrm{C}>\mathrm{A}$ polymorphism. Compared with the $\mathrm{CC}$ genotype, the variant AA and the CA genotypes significantly decreased the risk of developing HCC; the adjusted OR was 0.51 $(95 \% \mathrm{CI}=0.28-0.92)$ and $0.75(95 \% \mathrm{CI}=0.58-0.98)$, respectively (Table 1).

We further divided the data into subgroups based on age, sex, smoking status, alcohol drinking status, HBV carrier state and family history of cancer. We evaluated the $\mathrm{HCC}$ risk for each subgroup by estimating the ORs associated with the combined VEGF -2578 CA/ AA variant genotypes compared with the VEGF -2578 CC genotypes, with adjustment for the aforementioned variables (Table 2). When stratifying by age, we found that the VEGF -2578 CA/AA variant genotypes was associated with a significantly risk of HCC among both older people ( $\geq 55$ years old) and younger subjects $(<55$ years old). Similarly, When stratifying by HBV carrier state, we found that the VEGF -2578 CA/AA variant genotype was associated with a significantly risk of HCC among both HBsAg-positive individuals and HBsAg-negative people. However, in the subgroup analyses by sex, smoking status, alcohol drinking status and family history of cancer, the risk associated with the combined CA/AA variant genotype was more evident for men (adjusted $\mathrm{OR}=0.43$, $95 \% \mathrm{CI}=0.29-0.63$ ), never-smokers (adjusted $\mathrm{OR}=0.57$, $95 \% \mathrm{CI}=0.38-0.87$ ), never-drinkers (adjusted $\mathrm{OR}=0.57$, $95 \% \mathrm{CI}=0.40-0.82$ ), and subjects without family history of cancer (adjusted OR $=0.56,95 \% \mathrm{CI}=0.41-0.77$ ). No significant association was observed between the other three polymorphisms of the $V E G F$ gene and risk of HCC in any stratification analysis (data not shown).

\section{Genotype effects on postoperative recurrence of resected $\mathrm{HCC}$}

We also investigated the association between VEGF SNPs and postoperative recurrence of resected 
Table 1: VEGFA genotype and allele frequencies of the cases and controls and their association with risk of HCC

\begin{tabular}{|c|c|c|c|c|c|c|c|}
\hline Polymorphism & $\begin{array}{l}\text { Genotype } \\
\text { /allele }\end{array}$ & $\begin{array}{l}\text { HCC } \\
(n=476)\end{array}$ & $\begin{array}{l}\text { controls } \\
(n=526)\end{array}$ & $\begin{array}{l}\text { Crude OR } \\
95 \% \text { CI }\end{array}$ & $\begin{array}{c}P^{\mathrm{a}} \\
\text { value }\end{array}$ & $\begin{array}{l}\text { Adjusted } O^{b} \\
95 \% \text { CI }\end{array}$ & $\begin{array}{c}P^{\mathrm{c}} \\
\text { value }\end{array}$ \\
\hline VEGF & $\mathrm{CC}$ & $359(75.4)^{d}$ & $370(70.3)$ & 1.00 & & 1.00 & \\
\hline \multirow[t]{2}{*}{$936 \mathrm{C} / \mathrm{T}$} & $\mathrm{CT}$ & $112(23.5)$ & $140(26.6)$ & $0.83[0.62,1.10]$ & 0.188 & $0.84[0.60,1.19]$ & 0.325 \\
\hline & TT & $5(1.1)$ & $16(3.1)$ & $0.32[0.12,0.89]$ & 0.021 & $0.54[0.17,1.70]$ & 0.295 \\
\hline Genotypes & $\mathrm{CT}$ and TT & $117(24.6)$ & $156(29.7)$ & $0.77[0.58,1.02]$ & 0.071 & $0.81[0.58,1.13]$ & 0.221 \\
\hline Alleles & $\mathrm{T}$ & 0.128 & 0.163 & & & & \\
\hline VEGF & GG & $162(34.0)$ & $200(38.0)$ & 1.00 & & 1.00 & \\
\hline \multirow[t]{2}{*}{$634 \mathrm{G} / \mathrm{C}$} & $\mathrm{GC}$ & $232(48.8)$ & $248(47.2)$ & $1.16[0.88,1.52]$ & 0.302 & $1.10[0.79,1.53]$ & 0.583 \\
\hline & $\mathrm{CC}$ & $82(17.2)$ & $78(14.8)$ & $1.30[0.89,1.88]$ & 0.170 & $1.13[0.73,1.75]$ & 0.590 \\
\hline Genotypes & $\mathrm{GC}$ and $\mathrm{CC}$ & $314(66.0)$ & $326(62.0)$ & $1.19[0.92,1.54]$ & 0.189 & $1.11[0.81,1.51]$ & 0.516 \\
\hline Alleles & $\mathrm{C}$ & 0.416 & 0.384 & & & & \\
\hline VEGF & GG & $254(53.4)$ & $296(56.3)$ & 1.00 & & 1.00 & \\
\hline \multirow[t]{2}{*}{$1612 \mathrm{G} / \mathrm{A}$} & GA & $188(39.5)$ & $198(37.6)$ & $1.11[0.85,1.44]$ & 0.447 & $1.22[0.90,1.67]$ & 0.203 \\
\hline & AA & $34(7.1)$ & $32(6.1)$ & $1.24[0.74,2.06]$ & 0.412 & $1.16[0.64,2.11]$ & 0.628 \\
\hline Genotypes & GA and AA & $222(46.6)$ & $230(43.7)$ & $1.13[0.88,1.44]$ & 0.355 & $1.21[0.90,1.63]$ & 0.209 \\
\hline Alleles & A & 0.269 & 0.249 & & & & \\
\hline VEGF & $\mathrm{CC}$ & $301(63.2)$ & $290(55.1)$ & 1.00 & & 1.00 & \\
\hline \multirow[t]{2}{*}{$2578 \mathrm{C} / \mathrm{A}$} & CA & $157(33.0)$ & $202(38.4)$ & $0.75[0.58,0.98]$ & 0.031 & $0.72[0.53,0.98]$ & 0.041 \\
\hline & AA & $18(3.8)$ & $34(6.5)$ & $0.51[0.28,0.92]$ & 0.024 & $0.48[0.24,0.96]$ & 0.038 \\
\hline Genotypes & $\mathrm{CA}$ and $\mathrm{AA}$ & $175(36.8)$ & $236(44.9)$ & $0.71[0.55,0.92]$ & 0.009 & $0.69[0.51,0.93]$ & 0.014 \\
\hline Alleles & A & 0.203 & 0.257 & & & & \\
\hline
\end{tabular}

a, $P$ value for crude odds ratio (OR) and $95 \%$ confidence interval $(\mathrm{CI})$.

$\mathrm{b}$, Adjusted for age, gender, HBV carrier state, family history of cancer, smoking, and drinking status.

c, $P$ value for adjusted odds ratio (OR) and $95 \%$ confidence interval (CI).

$\mathrm{d}$, Values in parentheses indicate percentages.

HCC. As shown in Table 3, we found that only the VEGF $-2578 \mathrm{C}>\mathrm{A}$ polymorphism was significantly associated with the postoperative recurrence of HCC. The variant genotypes showed a lower recurrence rate than that of the wild genotype $\left(\mathrm{OR}_{\mathrm{AC}+\mathrm{AA} \text { vs. CC}}, 0.51 ; 95 \% \mathrm{CI}, 0.29-0.88\right.$; $P=0.017)$.

\section{Genotype effects on overall survival of resected HCC}

In order to eliminate the influence of different treatment methods to $\mathrm{HCC}$ prognosis, we detected the SNPs genotype effects on OS of curative resected HCC. There were 52 deaths $(23.4 \%)$ among the 222 resected HCC cases and the median survival time (MST) of these cases was 53 months in the cohort patients. By the KaplanMeier analysis, a tumor size larger than $5 \mathrm{~cm}$, the diffuse type of HCC, advanced tumor staging (both TNM III/IV stages and BCLC B/C/D stages), the presence of portal vein invasion, lymph node metastasis, microvascular invasion, and microsatellite nodule, and advanced edmondson grade (III and IV) were factors that were significantly associated with reduced OS (Supplementary Table 5). Table 4 and Figure 1 shows the association between VEGF VEGF -936C $>$ T, $-634 \mathrm{G}>\mathrm{C},-1612 \mathrm{G} / \mathrm{A}$ and $-2578 \mathrm{C}>\mathrm{A}$ genotypes and $\mathrm{OS}$ of the resected HCC patients. Of the 4 SNPs evaluated in the VEGF gene, we found that only the VEGF -2578 C $>$ A polymorphism was significantly associated with the survival of the resected $\mathrm{HCC}$ patients (AA/AC vs. CC, $P=0.001$ ).

Furthermore, we also conducted a multivariate analysis of the effects of genotype on survival using Cox proportional hazards models adjusted for other important clinical factors which were proved to be associated with OS in the univariate analysis. We re-evaluated the associations for each $-936 \mathrm{C}>\mathrm{T},-634 \mathrm{G}>\mathrm{C},-1612 \mathrm{G} / \mathrm{A}$ and $-2578 \mathrm{C}>\mathrm{A}$ following adjustments for the clinical characteristics. As shown in Table 5, the $-2578 \mathrm{C}>\mathrm{A}$ remained as significant independent predictors of survival among $\mathrm{HCC}$ patients (AA/AC vs. CC; adjusted $\mathrm{HR}=0.27$, $95 \% \mathrm{CI}=0.13-0.52$ ). Moreover, among the important clinical factors, only the diffuse type of HCC, the presence of portal vein invasion, microvascular invasion, and advanced edmondson grade (III and IV) remained as significant independent predictors of reduced survival. In addition, we stratified the OS of patients according to VEGF 2578 genotypes by different tumor stages which were represented in Figure 2. The predictive power of 
Table 2: Associations and stratification analysis of VEGFA $2578 \mathrm{C} / \mathrm{A}$ polymorphism and HCC risk

\begin{tabular}{|c|c|c|c|c|c|}
\hline Variable & Genotypes & $\begin{array}{l}\mathrm{HCC}(\%) \\
n=476\end{array}$ & $\begin{array}{l}\text { Control(\%) } \\
n=526\end{array}$ & $\begin{array}{l}\text { Adjusted OR } \\
(95 \% \text { CI) }\end{array}$ & $P$ value \\
\hline \multicolumn{6}{|l|}{ Age } \\
\hline \multirow[t]{2}{*}{$<55$ years } & $\mathrm{CC}$ & $169(62.6)$ & $175(55.9)$ & 1.00 & \\
\hline & $\mathrm{CA}+\mathrm{AA}$ & $101(37.4)$ & $138(44.1)$ & $0.57(0.38,0.87)$ & 0.009 \\
\hline \multirow[t]{2}{*}{$\geq 55$ years } & $\mathrm{CC}$ & $132(64.1)$ & $115(54.0)$ & 1.00 & \\
\hline & $\mathrm{CA}+\mathrm{AA}$ & $74(35.9)$ & $98(46.0)$ & $0.53(0.33,0.84)$ & 0.007 \\
\hline \multicolumn{6}{|l|}{ Gender } \\
\hline \multirow[t]{2}{*}{ Female } & $\mathrm{CC}$ & $76(61.3)$ & $87(62.1)$ & 1.00 & \\
\hline & $\mathrm{CA}+\mathrm{AA}$ & $48(38.7)$ & $53(37.9)$ & $1.06(0.60,1.88)$ & 0.840 \\
\hline \multirow[t]{2}{*}{ Male } & $\mathrm{CC}$ & $225(63.9)$ & $203(52.6)$ & 1.00 & \\
\hline & $\mathrm{CA}+\mathrm{AA}$ & $127(36.1)$ & $183(47.4)$ & $0.43(0.29,0.63)$ & 0.000 \\
\hline \multicolumn{6}{|l|}{ Smoking } \\
\hline \multirow{2}{*}{ Yes } & $\mathrm{CC}$ & $159(62.1)$ & $97(54.5)$ & 1.00 & \\
\hline & $\mathrm{CA}+\mathrm{AA}$ & $97(37.9)$ & $81(45.5)$ & $0.61(0.38,1.00)$ & 0.054 \\
\hline \multirow[t]{2}{*}{ No } & $\mathrm{CC}$ & $142(64.5)$ & $193(55.5)$ & 1.00 & \\
\hline & $\mathrm{CA}+\mathrm{AA}$ & $78(35.5)$ & $155(44.5)$ & $0.57(0.38,0.87)$ & 0.008 \\
\hline \multicolumn{6}{|l|}{ Drinking } \\
\hline \multirow[t]{2}{*}{ Yes } & $\mathrm{CC}$ & $79(60.8)$ & $71(57.7)$ & 1.00 & \\
\hline & $\mathrm{CA}+\mathrm{AA}$ & $51(39.2)$ & $52(42.3)$ & $0.61(0.32,1.18)$ & 0.143 \\
\hline \multirow[t]{2}{*}{ No } & $\mathrm{CC}$ & $222(64.2)$ & $219(54.3)$ & 1.00 & \\
\hline & $\mathrm{CA}+\mathrm{AA}$ & $124(35.8)$ & $184(45.7)$ & $0.57(0.40,0.82)$ & 0.002 \\
\hline \multicolumn{6}{|l|}{ HBV } \\
\hline \multirow[t]{2}{*}{$\operatorname{HbsAg}(+)$} & $\mathrm{CC}$ & $194(60.2)$ & $37(43.5)$ & 1.00 & \\
\hline & $\mathrm{CA}+\mathrm{AA}$ & $128(39.8)$ & $48(56.5)$ & $0.53(0.32,0.86)$ & 0.011 \\
\hline \multirow[t]{2}{*}{$\operatorname{HbsAg}(-)$} & $\mathrm{CC}$ & $107(69.5)$ & $253(57.4)$ & 1.00 & \\
\hline & $\mathrm{CA}+\mathrm{AA}$ & $47(30.5)$ & $188(42.6)$ & $0.60(0.40,0.89)$ & 0.010 \\
\hline \multicolumn{6}{|c|}{ Family history of cancer } \\
\hline \multirow[t]{2}{*}{ Yes } & $\mathrm{CC}$ & $29(64.4)$ & $24(51.1)$ & 1.00 & \\
\hline & $\mathrm{CA}+\mathrm{AA}$ & $16(35.6)$ & $23(48.9)$ & $0.48(0.16,1.46)$ & 0.194 \\
\hline \multirow[t]{2}{*}{ No } & $\mathrm{CC}$ & $272(63.1)$ & $266(55.5)$ & 1.00 & \\
\hline & $\mathrm{CA}+\mathrm{AA}$ & $159(36.9)$ & $213(44.5)$ & $0.56(0.41,0.77)$ & 0.000 \\
\hline
\end{tabular}

Table 3: SNPs of VEGFA genes and postoperative recurrence of resected HCC

\begin{tabular}{|c|c|c|c|c|c|c|}
\hline SNP & Genotype & $\begin{array}{l}\text { Recur }(+), \\
n(\%)\end{array}$ & $\begin{array}{l}\text { Recur (-), } \\
n(\%)\end{array}$ & $\begin{array}{l}\text { Adjusted } \\
\mathrm{OR}^{\dagger}\end{array}$ & $95 \% \mathrm{CI}$ & $p$ value \\
\hline VEGF & GG & $42(38.5)$ & 37 (32.7) & Ref & & \\
\hline 634G/C & $\mathrm{GC} / \mathrm{CC}$ & $67(61.5)$ & $76(67.3)$ & 0.78 & $0.45-1.37$ & 0.395 \\
\hline VEGF & $\mathrm{CC}$ & $82(75.2)$ & $86(76.1)$ & Ref & & \\
\hline $936 \mathrm{C} / \mathrm{T}$ & $\mathrm{CT} / \mathrm{TT}$ & $27(24.8)$ & $27(23.9)$ & 1.06 & $0.57-1.99$ & 0.846 \\
\hline VEGF & GG & $64(58.7)$ & $61(54.0)$ & Ref & & \\
\hline $1612 \mathrm{G} / \mathrm{A}$ & GA/AA & $45(41.3)$ & $52(46.0)$ & 0.89 & $0.52-1.54$ & 0.675 \\
\hline VEGF & $\mathrm{CC}$ & $72(66.1)$ & $57(50.4)$ & Ref & & \\
\hline $2578 \mathrm{C} / \mathrm{A}$ & $\mathrm{CA} / \mathrm{AA}$ & $37(33.9)$ & $56(49.6)$ & 0.51 & $0.29-0.88$ & 0.017 \\
\hline
\end{tabular}

SNP, single nucleotide polymorphism; HCC, hepatocelluar carcinoma; Recur, postoperative recurrence; OR, odds ratio; CI, confidence interval.

${ }^{\dagger}$ Adjusted for age, gender, HBV carrier state, family history of cancer, smoking, and drinking status. 
Table 4: Overall survival by VEGFA genotype in patients with resected HCC

\begin{tabular}{llllcc}
\hline Genotype & Cases, $\boldsymbol{n}$ & Deaths, $\boldsymbol{n}$ & MST (Mo) & $\mathbf{9 5 \%}$ CI (Mo) & P value \\
\hline VEGF 634G/C* & & & & & 0.385 \\
GG & 79 & 23 & 53 & $43.4-62.6$ & \\
GC/CC & 143 & 29 & 51 & $48.4-54.6$ & 0.740 \\
VEGF 936 C/T* & & & & $48.3-54.0$ & \\
CC & 168 & 37 & 51 & $46.5-53.4$ & 0.213 \\
CT/TT & 54 & 15 & 50 & & \\
VEGF 1612G/A* & & & & $43.9-56.1$ & \\
GG & 125 & 34 & 50 & $49.8-56.8$ & \\
GA/AA & 97 & 18 & 53 & & \\
VEGF 2578C/A* & & & & $41.7-54.3$ & \\
CC & 129 & 38 & 48 & $51.7-58.4$ & \\
CA/AA & 93 & 14 & 55 &
\end{tabular}

HCC, hepatocelluar carcinoma; MST, median survival time; Mo, months; CI, confidence interval.

"Mean survival time was provided when MST could not be calculated.

genotype for survival was statistically apparent except for patients with TNM stage III and IV.

\section{VEGF genotypes and VEGF expression levels}

The median serum concentration of VEGF detected was $383.02 \mathrm{pg} / \mathrm{ml}$ (range 88.96-1200.37 $\mathrm{pg} / \mathrm{ml}$ ) in

\section{A}
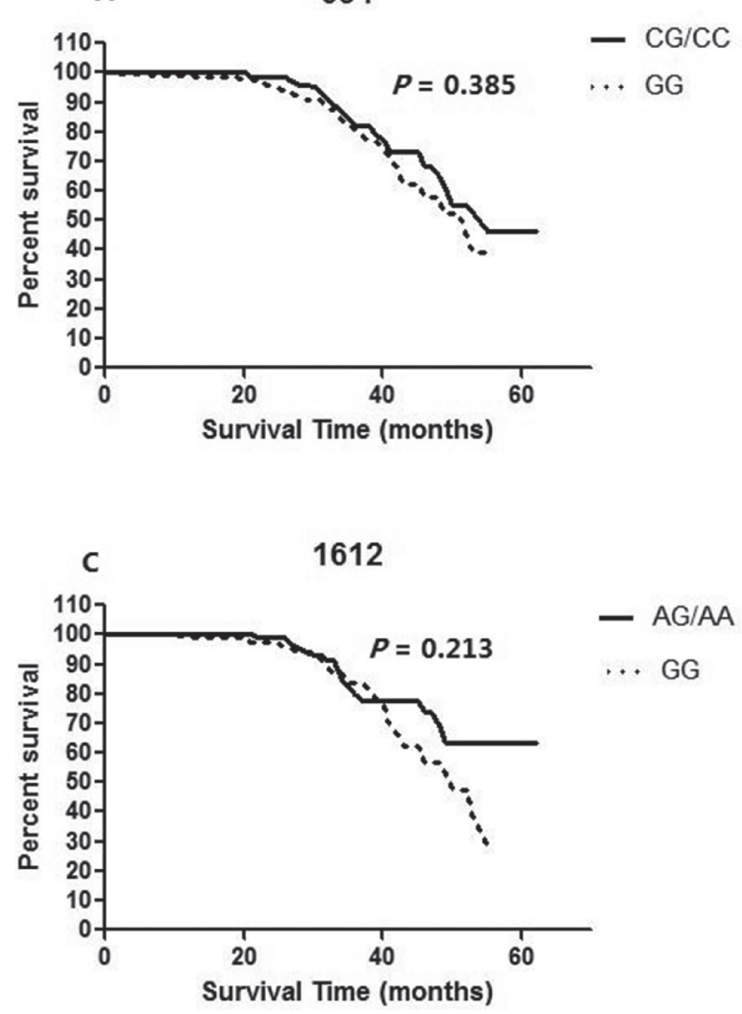

HCC patients $(n=60)$ and $146.89 \mathrm{pg} / \mathrm{ml}$ (range 45.01$646.33 \mathrm{pg} / \mathrm{ml})$ in healthy control subjects $(n=60)$. The serum levels of VEGF detected in HCC patients were significantly higher than those in the healthy control subjects $(P<0.000)$. However, when studying the relationship between the VEGF polymorphisms and serum levels among HCC patients and healthy controls, we found
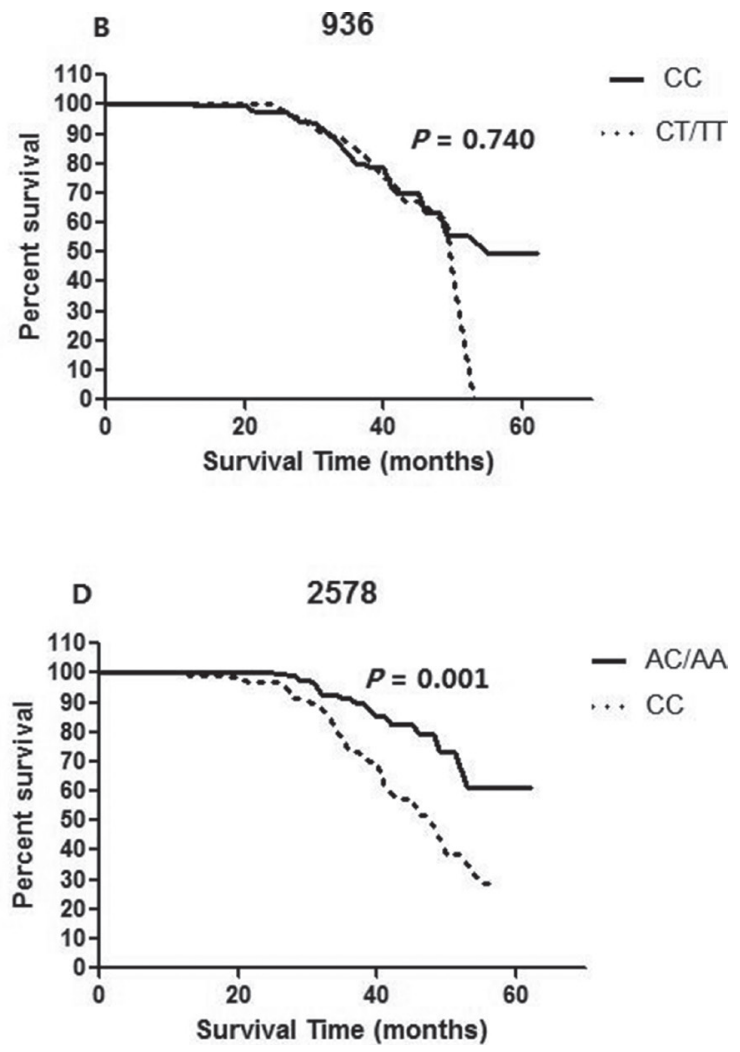

Figure 1: Kaplan-Meier curves of overall survival of curative resected HCC with each (A) 634 genotype, (B) 936 genotype, (C) 1612 genotype and (D) 2578 genotype of the VEGF gene. $P$ value was calculated using a log-rank test. 
Table 5: Cox multivariate regression analysis of potential factors for overall survival in patients with resected $\mathrm{HCC}$

\begin{tabular}{llll}
\hline Variables & Adjusted HR* & (95\% CI)* & P* \\
\hline Tumor size (> 5 cm vs. $\leq 5 \mathrm{~cm}$ ) & 1.099 & $0.364-3.318$ & 0.867 \\
Tumor type ( diffuse vs. nodular ) & 3.887 & $1.861-8.122$ & 0.000 \\
Portal vein invasion (yes vs.no) & 8.622 & $1.403-52.999$ & 0.020 \\
Lymph node metastasis (yes vs.no) & 3.566 & $0.610-20.836$ & 0.158 \\
Microvascular invasion (yes vs.no) & 3.471 & $1.628-7.401$ & 0.001 \\
Microsatellite nodule (yes vs.no) & 1.572 & $0.667-3.703 \mathrm{~W}$ & 0.301 \\
Edmondson grade (III/IV vs.I/II) & 2.549 & $1.264-5.138$ & 0.009 \\
VEGFA 2578 C/A (AA/AC vs. CC) & 0.265 & $0.134-0.524$ & 0.000 \\
\hline
\end{tabular}

*HR (95\% confidence interval [CI]) and $P$ values for the 2578 genotype for overall survival were adjusted according to important clinical characteristics.

no significant association between VEGF SNPs genotype and serum levels of VEGF.

\section{DISCUSSION}

In this study, we investigated the association of VEGF $-936 \mathrm{C}>\mathrm{T},-634 \mathrm{G}>\mathrm{C},-1612 \mathrm{G} / \mathrm{A}$ and $-2578 \mathrm{C}>\mathrm{A}$ polymorphisms with susceptibility and clinical outcome of HCC in a Chinese Han population. To the best of our knowledge, this is the first study that has investigated the association between SNPs of VEGF genes and the occurrence and clinical outcomes of HCC simultaneously. Our results showed that the VEGF $-2578 \mathrm{C}>\mathrm{A}$ polymorphism was significantly associated with HCC susceptibility among both HBsAg-positive and HBsAg- negative individuals at different ages. Despite the serum levels of VEGF detected in HCC patients were significantly higher than those in the healthy control subjects, we found no significant association between VEGF SNPs genotype and serum levels of VEGF. In addition, we demonstrated that the VEGF $-2578 \mathrm{C}>\mathrm{A}$ polymorphism was associated with significantly
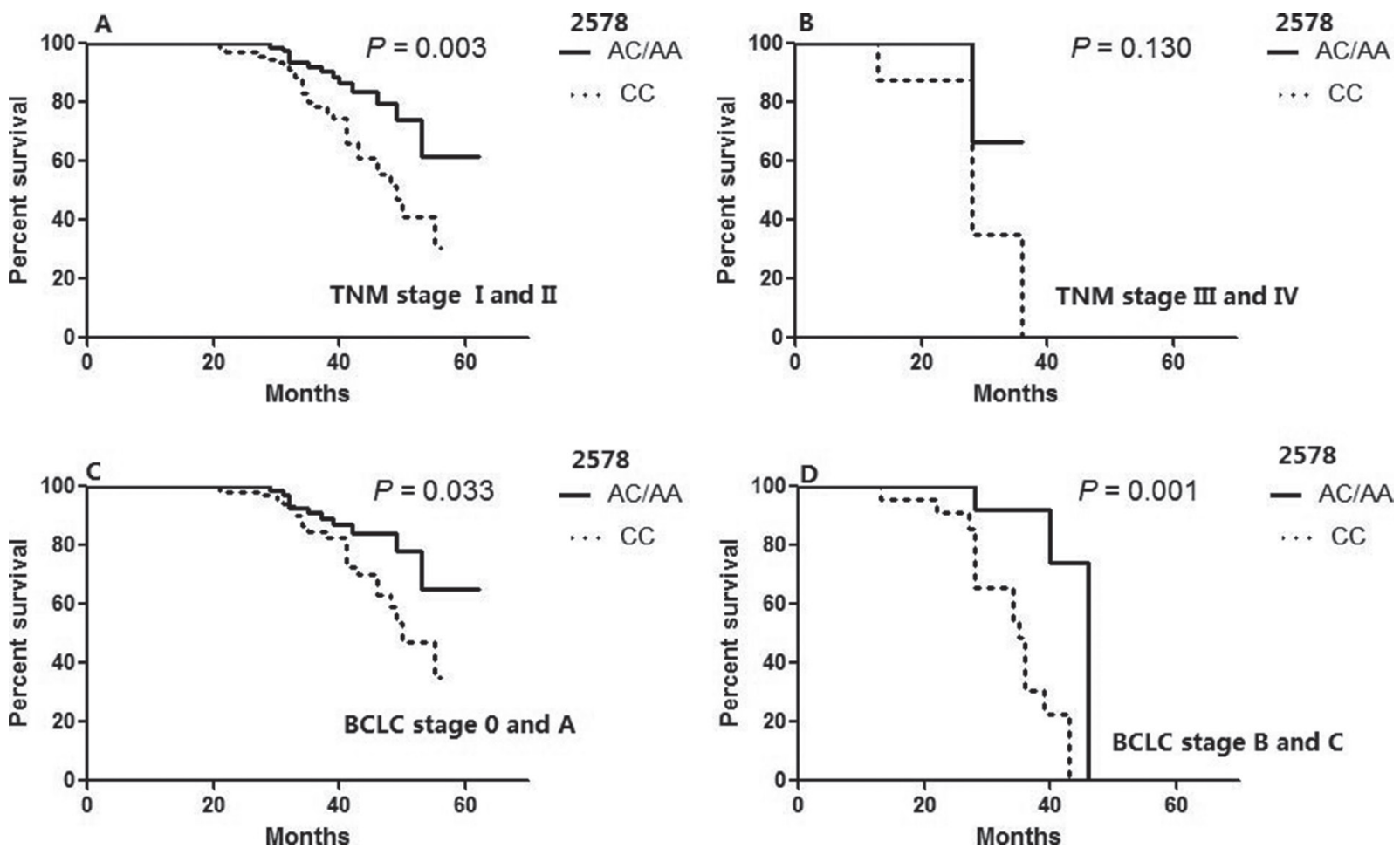

2578<smiles>[GeH3]</smiles>

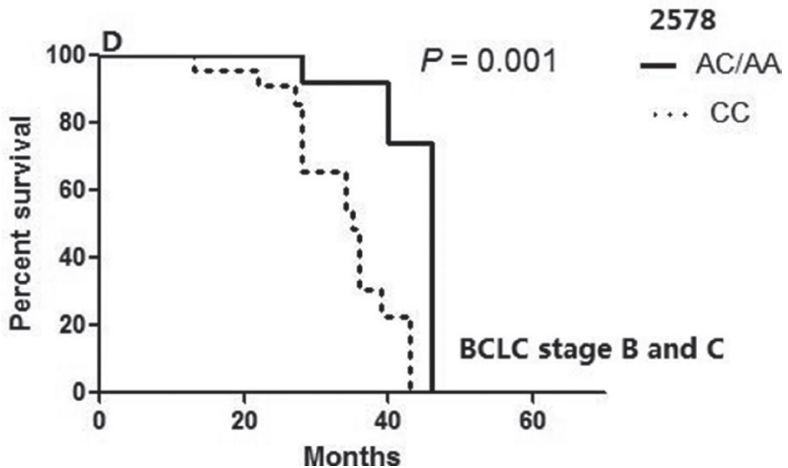

Figure 2: Overall survival of patients with resected HCC according to VEGF 2578 genotypes in different tumor stages. (A) TNM stage I and II (B) TNM stage III and IV (C) BCLC stage 0 and A(D) BCLC stage B and C. $P$ value was calculated using a log-rank test. 
decreased postoperative recurrence and improved OS of resected HCC patients.

In our study, the polymorphism of VEGF $-2578 \mathrm{C}>\mathrm{A}$ was found to be associated with the development and the OS in resected HCC patients. The exact mechanism for the correlation needs further exploring because we found no significant association between VEGF SNPs genotype and serum levels of VEGF. However, previous published studies on the functions of the VEGF $-2578 \mathrm{C}>\mathrm{A}$ SNP together with their genetic variants may help us understand the potential roles of the polymorphism. The $-2578 \mathrm{C} /$ A polymorphism, which was a functional SNP in VEGF gene promoter region, are associated with altered VEGF secretion [18]. Moreover, Shahbazi et al [32] reported that the genotype C/C of the SNP rs699947 in the -2578 nucleotide position of the VEGF promoter, had been associated with higher levels of VEGF in blood mononuclear cells. In addition, Poon et al [16] found that a high serum level of VEGF is a predictor of poor outcome of HCC. Therefore, it is biologically plausible that VEGF $-2578 \mathrm{C} / \mathrm{A}$ polymorphism was associated with a decreased $\mathrm{HCC}$ risk and the increased OS in resected $\mathrm{HCC}$ patients through a low serum level of VEGF caused by the 2578 $\mathrm{C}$ to A variant.

In recent years, the association between VEGF polymorphism and HCC risk has been investigated, however, the results are inconsistent. In 2010, He et al [27] firstly reported that an 18-bp insertion/deletion polymorphism (rs35569394) in the promoter region of VEGF gene was not associated with susceptibility to HCC in Chinese. However, Giacalone et al [28] found that carriers with the $\mathrm{C}$ allele of $936 \mathrm{C} / \mathrm{T}$ in the VEGF gene were more frequent in $\mathrm{HCC}$ versus liver cirrhosis and suggested that this SNP might predispose to the development of HCC. Moreover, Wu et al [15] demonstrated that two promoter SNPs (rs833061 and rs 1570360) in VEGF were associated with susceptibility to $\mathrm{HCC}$ and the $936 \mathrm{C} / \mathrm{T}$ polymorphism was not associated with HCC. Our study found that the VEGF $-2578 \mathrm{C}>\mathrm{A}$ polymorphism was significantly associated with $\mathrm{HCC}$ and the $936 \mathrm{C} / \mathrm{T}$ polymorphism was not associated with $\mathrm{HCC}$ risk. The conflicting results could be attributable to the differences in demography, ethnicity, lifestyles, and other methodologic factors in the studies, such as small sample size, inadequate adjustment for confounding factors.

Alcohol consumption and cigarette smoking are important environmental risk factors for $\mathrm{HCC}[33,34]$. In addition, age, gender and family history of cancer might also affect the risk of HCC. Unlike Wu et al's study [15], we also performed subgroup analyses by these risk factors. We found that the decrease in risk was more evident among men, never-smokers, never-drinkers, and subjects without family history of cancer for the VEGF $-2578 \mathrm{C}>$ A polymorphism. Although the exact mechanism for the results of subgroup analyses were as yet unknown, some possibilities should be considered. Previous studies
$[33,34]$ had proved that drinking and smoking were major risk factor for HCC. Especially in 2004, the International Agency for Research on Cancer had classified HCC as one of the tobacco-related cancers [35]. The environment risk factors, such as drinking and smoking, could increased the risk of $\mathrm{HCC}$; while the VEGF -2578C/A polymorphism was associated a decreased risk of HCC. Therefore, the protect effect for HCC by the VEGF $-2578 \mathrm{C} / \mathrm{A}$ polymorphism may be eliminated by the environment risk factors after gene-environment interaction.

We also performed functional analysis for the VEGF SNPs to attempt to clarify the mechanism for the correlation between VEGF SNPs and risk and clinical outcome of HCC by measuring the serum VEGF levels among both HCC patients and healthy controls. Although the serum levels of VEGF detected in HCC patients were significantly higher than those in the healthy control subjects $(P<0.000)$, no significant association between VEGF SNPs genotype and serum levels of VEGF was observed. This may be because the simple size for measuring the serum VEGF levels was too small to detect the association between VEGF SNPs genotype and serum levels of VEGF. In addition, another explanation for the negative correlation was that the serum VEGF concentration could be regulated by many clinical factors and cytokines except for the VEGF gene polymorphism $[29,36]$.

In this study, several limitations need to be addressed. Firstly, these results should be interpreted with caution because the population only from Chinese Han, which reduces the possibility of confounding from ethnicity, but it does not permit extrapolation of the results to other ethnic groups because the allele frequency patterns of VEGF polymorphisms vary greatly between different ethnic groups. Secondly, the study sample size was relative small, especially for the association between VEGFA polymorphism and HCC prognosis.

In summary, this study investigated the association of VEGFA -936C $>$ T, $-634 \mathrm{G}>\mathrm{C},-1612 \mathrm{G} / \mathrm{A}$ and $-2578 \mathrm{C}>\mathrm{A}$ polymorphisms with risk and clinical outcome of HCC simultaneously in the same cohort patients and found the VEGFA - 2578C $>$ A polymorphism was associated with a significantly decreased HCC risk and improved OS of resected HCC patients. These results suggest that the VEGFA 2578 C/A polymorphism may play a potential role in the development and clinical outcome of HCC among Chinese Han population.

\section{MATERIALS AND METHODS}

\section{Study population}

Our population had been described previously [37]. Supplementally, identification of the stage of tumor is based on the tumor-node-metastasis (TNM) classification system which was promulgated by the American Joint Committee on Cancer and International Union Against 
Cancer in 2010 [38] and Barcelona-Clinic-Liver-Cancer (BCLC) stages [39]. Vascular invasion was recognized by the presence of thrombus adjacent to the tumor in portal and hepatic vein system with vague boundary confirmed by at least two imaging modalities [40]. Routine chest CT scan was performed to detect metastatic lesion(s). Bone metastasis of HCC was surveyed by bone scan and confirmed by MRI. Lymph node involvement was diagnosed by CT/MRI and/or postoperative pathology. Clinical information such as age, sex, tumor size, number of tumors, nodal invasion, metastasis, existence of vascular invasion, Child-Pugh classification, treatment modalities and the results of clinical laboratory tests were collected from the medical records. Based on Child-Pugh classification, the location of the tumor within the liver and modified TNM staging, we initially treated patients with one of four treatment modalities: liver resection, radiofrequency ablation, transarterial chemoe mbolization, or conservative management (such as sorafenib). The overall survival time was calculated from the date of tumor resection or the first local treatment to the date of death or to the last follow-up. Informed consents were obtained according to the Declaration of Helsinki. A written informed consent was obtained from each subject involved in the study. The study was approved by the Ethics Committee of Sichuan University.

\section{Genotype analyses}

The genomic DNA was isolated from whole blood samples using the whole blood DNA kit (Biotake corporation). The concentration of DNA was diluted to $20 \mathrm{ng} / \mu \mathrm{L}$ for working solutions and the isolated DNA was stored at $-20^{\circ} \mathrm{C}$. SNP genotyping was performed using MassARRAY system (Sequenom, San Diego, CA, USA) by means of matrix assisted laser desorption ionisation-time of flight mass spectrometry method (MALDI-TOF) according to the manufacturers instructions. Primers for PCR and single base extension were designed by using Assay Designer software package (Sequenom) (Supplementary Table 1). The detailed process for SNP genotyping could be found in elsewhere [37] and the Supplementary Table 2. For quality control, genotyping was performed without knowing the subjects' status, and a 5\% random samples were genotyped twice for each locus. To further validate the genotyping assay of MALDI-TOF for the four loci, about $5 \%$ of samples genotyped with MALDI-TOF were further confirmed by direct sequencing method. Among the 500 cases and 550 controls with DNA samples, the genotyping was successful for the four loci in 476 cases and 526 controls which were included in the final analyses.

\section{Serum VEGF levels}

Blood samples were obtained from subjects with and without $\mathrm{HCC}$, centrifuged and stored at $-80^{\circ} \mathrm{C}$ until analysis. Commercial ELISA kit (R\&D Systems,
Minneapolis, MN, USA) was used according to the instructions of the manufacturer to measure VEGF-A concentrations in serum. Briefly, $100 \mu \mathrm{L}$ serum samples and standards were added to a 96-well antibody-coated plate. Then the plate was washed three times with wash buffer. After then, the biotin conjugate-labeled second antibody was added in plate and stored at room temperature. One hour later the plate was washed again and the conjugate was added, sealed, shaken and stored at room temperature for 30 minutes and then washed three times again. The substrate was added in all plates and stored at room temperature out of light for 10 minutes and then the stop solution was added. The absorbance was measured at $450 \mathrm{~nm}$.

\section{Statistical analysis}

Hardy-Weinberg equilibrium (HWE) was tested by a goodness-of-fit $\chi^{2}$ test, to compare the observed genotype frequencies to the expected ones among the control subjects. The associations between VEGF genotypes and risk of $\mathrm{HCC}$ were estimated by computing the odds ratios (ORs) and their 95\% confidence intervals (CIs) from both univariate and multivariate logistic regression analyses with adjustment for age, sex, HBV carrier state, alcohol intake, smoking status, and family history of cancer. Differences in VEGF serum levels among patients with HCC versus control subjects were examined using the Mann-Whitney $U$ test. The relation of SNPs to the overall survival (OS) was identified using the KaplanMeier method with the log-rank test and Cox proportional hazard model. All statistical analyses were two sided and performed using SPSS version 16.0 for Windows statistical software (SPSS Inc., Chicago, IL, USA). A $P$-value of $<0.05$ was considered as statistically significant.

\section{CONFLICTS OF INTEREST}

None declared.

\section{FINANCIAL SUPPORT}

This work was supported by grants from the National Natural Science Foundation of China (No. 81602910) and the Application Foundation Project of Science and Technology Agency in Sichuan Province (No 2012JY0079).

\section{REFERENCES}

1. Torre LA, Bray F, Siegel RL, Ferlay J, Lortet-Tieulent J, Jemal A. Global cancer statistics, 2012. CA Cancer J Clin. 2015; 65:87-108.

2. London WT, McGlynn KA. Liver cancer. In: Schottenfeld D, Fraumeni J Jr, eds. Cancer Epidemiology and Prevention. 3rded. New York: Oxford University Press; 2006; 763-786. 
3. Aravalli RN, Steer CJ, Cressman EN. Molecular mechanisms of hepatocellular carcinoma. Hepatology. 2008; 48:2047-63.

4. Chen CJ, Chen DS. Interaction of hepatitis B virus, chemical carcinogen, and genetic susceptibility: multistage hepatocarcinogenesis with multifactorial etiology. Hepatology. 2002; 36:1046-9.

5. Nissen NN, Martin P. Hepatocellular carcinoma: the highrisk patient. J Clin Gastroenterol. 2002; 35:S79-85.

6. Bowen DG, Walker CM. Adaptive immune responses in acute and chronic hepatitis $\mathrm{C}$ virus infection. Nature. 2005; 436:946-952.

7. Pang RW, Joh JW, Johnson PJ, Monden M, Pawlik TM, Poon RT. Biology of hepatocellular carcinoma. Ann Surg Oncol. 2008; 15:962-971.

8. Wang L, Wang WL, Zhang Y, Guo SP, Zhang J, Li QL. Epigenetic and genetic alterations of PTEN in hepatocellular carcinoma. Hepatol Res. 2007; 37:389-396.

9. Turati F, Edefonti V, Talamini R, Ferraroni M, Malvezzi M, Bravi F, Franceschi S, Montella M, Polesel J, Zucchetto A, La Vecchia C, Negri E, Decarli A. Family history of liver cancer and hepatocellular carcinoma. Hepatology. 2012; 55:1416-25.

10. Zhong DN, Ning QY, Wu JZ, Zang N, Wu JL, Hu DF, Luo SY, Huang AC, Li LL, Li GJ. Comparative proteomic profiles indicating genetic factors may involve in hepatocellular carcinoma familial aggregation. Cancer Sci. 2012; 103:1833-8.

11. Bruix J, Sherman M, Llovet JM, Beaugrand M, Lencioni R, Burroughs AK, Christensen E, Pagliaro L, Colombo M, Rodés J. EASL Panel of Experts on HCC. Clinical management of hepatocellular carcinoma. Conclusions of the Barcelona-2000 EASL conference. European Association for the Study of the Liver. J Hepatol. 2001; 35:421-430.

12. Bhattacharya R, Sinha S, Yang SP, Patra C, Dutta S, Wang E, Mukhopadhyay D. The neurotransmitter dopamine modulates vascular permeability in the endothelium. J Mol Signal. 2008; 3:14.

13. Kaumaya PT, Foy KC. Peptide vaccines and targeting HER and VEGF proteins may offer a potentially new paradigm in cancer immunotherapy. Future Oncol. 2012; 8:961-87.

14. Jain L, Vargo CA, Danesi R, Sissung TM, Price DK, Venzon D, Venitz J, Figg WD. The role of vascular endothelial growth factor SNPs as predictive and prognostic markers for major solid tumors. Mol Cancer Ther. 2009; 8:2496-508.

15. Wu X, Xin Z, Zhang W, Wu J, Chen K, Wang H, Zhu X, Pan L, Li Z, Li H, Liu Y. Polymorphisms in the VEGFA promoter are associated with susceptibility to hepatocellular carcinoma by altering promoter activity. Int J Cancer. 2013; 133:1085-93.

16. Poon RT, Ho JW, Tong CS, Lau C, Ng IO, Fan ST. Prognostic significance of serum vascular endothelial growth factor and endostatin in patients with hepatocellular carcinoma. Br J Surg. 2004; 91:1354-60.
17. Vincenti V, Cassano C, Rocchi M, Persico G. Assignment of the vascular endothelial growth factor gene to human chromosome 6p21.3. Circulation. 1996; 93:1493-5.

18. Almawi WY, Saldanha FL, Mahmood NA, Al-Zaman I, Sater MS, Mustafa FE. Relationship between VEGFA polymorphisms and serum VEGF protein levels and recurrent spontaneous miscarriage. Hum Reprod. 2013; 28:2628-35.

19. Koukourakis MI, Papazoglou D, Giatromanolaki A, Bougioukas G, Maltezos E, Sivridis E. VEGF gene sequence variation defines VEGF gene expression status and angiogenic activity in non-small cell lung cancer.Lung Cancer. 2004; 46:293-8.

20. Liu C, Zhou X, Gao F, Qi Z, Zhang Z, Guo Y. Correlation of genetic polymorphism of vascular endothelial growth factor gene with susceptibility to lung cancer.Cancer Gene Ther. $2015 ; 22: 312-6$.

21. Jang MJ, Jeon YJ, Kim JW, Cho YK, Lee SK, Hwang SG, Oh D, Kim NK. Association of VEGF and KDR single nucleotide polymorphisms with colorectal cancer susceptibility in Koreans. Mol Carcinog. 2013; 52:E60-9.

22. Ma J, Hu W, Zhang P, Sun Y, Wang N, Teng X, Qiao Q. The Association Between VEGF +936C/T and $-634 \mathrm{G} / \mathrm{C}$ Polymorphisms and Breast Cancer Susceptibility, Tumor Growth, and Metastases: Evidence From 20,728 Subjects. Cancer Invest. 2015; 33:312-7.

23. Yang Y, Zhang X, Song D, Wei J. Association between vascular endothelial growth factor gene polymorphisms and bladder cancer risk. Mol Clin Oncol. 2014; 2:501-5.

24. Eng L, Azad AK, Qiu X, Kong QQ, Cheng D, Ying N, Tse A, Kuang Q, Dodbiba L, Renouf DJ, Marsh S, Savas S, Mackay HJ, et al. Discovery and validation of vascular endothelial growth factor (VEGF) pathway polymorphisms in esophageal adenocarcinoma outcome. Carcinogenesis. 2015; 36:956-62.

25. Ma N, Li LW, Cheng JL. Predictive value of vascular endothelial growth factor polymorphisms on the clinical outcome of renal cell carcinoma patients. Oncol Lett. 2015; 9:651-6.

26. Chen N, Ma CN, Zhao M, Zhang YJ. Role of VEGF gene polymorphisms in the clinical outcome of non-small cell lung cancer. Genet Mol Res. 2015; 14:16006-11.

27. He Y, Ni J, Chen S, Jiang Y, Jia S, Gao Y. The vascular endothelial growth factor-2549 insertion/deletion polymorphism is not associated with susceptibility to hepatocellular carcinoma in Chinese. DNA Cell Biol. 2010; 29:393-6.

28. Giacalone A, Montalto G, Giannitrapani L, Balasus D, Terranova A, Cervello M, Soresi M, Marasà L. Association between single nucleotidepolymorphisms in the cyclooxygenase-2, tumor necrosis factor-alpha, and vascular endothelial growth factor-A genes, and susceptibility to hepatocellular carcinoma. Omics. 2011; 15:193-6.

29. Kong SY, Park JW, Lee JA, Park JE, Park KW, Hong EK, Kim CM. Association between vascular endothelial growth 
factor gene polymorphisms and survival in hepatocellular carcinoma patients. Hepatology. 2007; 46:446-55.

30. Scartozzi M, Faloppi L, Svegliati Baroni G, Loretelli C, Piscaglia F, Iavarone M,Toniutto P, Fava G, De Minicis S, Mandolesi A, Bianconi M, Giampieri R, Granito A, et al. VEGF and VEGFR genotyping in the prediction of clinical outcome for HCC patients receiving sorafenib: the ALICE-1 study. Int J Cancer. 2014; 135:1247-56.

31. Song J, Wang LZ, Li X, Jiang TP, An TZ, Xu M, Wu XP, Zhou S. Polymorphisms of vascular endothelial growth factor on prognosis in hepatocellular carcinoma patients receiving transcatheter arterial chemoembolization treatment. Genet Mol Res. 2014; 13:8946-53.

32. Shahbazi M, Fryer AA, Pravica V, Brogan IJ, Ramsay HM, Hutchinson IV, Harden PN. Vascular endothelial growth factor gene polymorphisms are associated with acute renal allograft rejection. J Am Soc Nephrol. 2002; 13:260-4.

33. Marrero JA, Fontana RJ, Fu S, Conjeevaram HS, Su GL, Lok AS. Alcohol, tobacco and obesity are synergistic risk factors for hepatocellular carcinoma. J Hepatol. 2005; 42:218-24.

34. Zhu K, Moriarty C, Caplan LS, Levine RS. Cigarette smoking and primary liver cancer: a population-based case- control study in US men. Cancer Causes Control. 2007; 18:315-21.

35. International Agency for Research on Cancer (IARC). Monographs on the evaluation of carcinogenic risks to humans: tobacco smoke and involuntary smoking. Lyon, France: IARC. 2004; 161-176.

36. Semela D DJ. Vascular endothelial growth factor signaling. In: Dufour JFCP, editor. Signaling pathways in liver diseases. Heidelberg: Springer-Verlag Berlin. 2005; 91-104.

37. Liu F, Wei YG, Luo LM, Wang WT, Yan LN, Wen TF, Xu MQ, Yang JY, Li B. Genetic variants of p21 and p27 and hepatocellular cancer risk in a Chinese Han population: a case-control study. Int J Cancer. 2013; 132:2056-64.

38. Edge SB, Byrd DR, Compton CC, Fritz AG, Greene FL, Trotti A. AJCC Cancer Staging Manual. 7th ed. Springer: New York. 2010; 191-200.

39. Forner A, Reig ME, de Lope CR, Bruix J. Current strategy for staging and treatment: the BCLC update and future prospects. Semin Liver Dis 2010;30:61-74.

40. Lee YH, Hsu CY, Huang YH, Hsia CY, Chiou YY, Su CW, Lin HC, Huo TI. Vascular invasion in hepatocellular carcinoma: prevalence, determinants and prognostic impact. J Clin Gastroenterol. 2014; 48 : 734-41. 